\title{
EVALUATING THE QUALITY OF OUTPUT IN EPSON INKJET PRINTER USING DESIGN OF EXPERIMENT METHOD
}

\author{
Ramakrishna Nayak ${ }^{1}$, Prathap Nayak ${ }^{2}$, Sandeep Nayak ${ }^{3}$, Vinod Kamath ${ }^{4}$ \\ Manipal, India
}

\begin{abstract}
The print quality in digital printer like Epson Stylus Pro 7900 is influenced by the various printing parameters and among these dot shape, screen resolution and paper are considered to be the major. The study conducted here was to evaluate the print quality in terms of the maximum number of color that it can reproduce on two different printing substrates at different dot shapes and resolutions by maintaining other printing parameters constant. Linearization and profiling of the Epson stylus Pro 7900 printer for all these combinations were completed using IT8.7-3 CMYK standard test target using Harlequin RIP V8.3 software. Then the color gamut volumes are analyzed using Taguchi's Design of experiments in Mini Tab software. This is done to evaluate the significant parameter that has a major influence on the color gamut. From the result obtained in the project it was concluded that change in the dot shapes and resolutions have less influence on the color gamut than the substrate's surface property. The glossy effect of the Epson proofing commercial 187 GSM paper has shown a significant change in the color gamut in comparison with the other paper properties and printing attributes. There are different paper substrates available which are mainly made for use in ink jet printer and since these digital devices are widely used for proofing and by photographers, it is better to take similar type of study to know the print quality on different paper substrates and making a profile for each paper is a must for achieving a consistent print in more economic way.
\end{abstract}

Keywords: Inkjet Printing, Color gamut, design of experiments, Print quality, Paper properties ***

\section{INTRODUCTION}

Advancements in digital printing has made it possible to use inkjet printers to get a high quality print for photography and proofing work. When we say a four color printing using cyan, magenta, yellow and black inks, it is not only these color inks that are involved in reproducing a desired print quality, but along with that there is a fifth analog color; the paper [1].

Printing on a paper substrate using inkjet process involves a number of process parameters that one should consider to get a quality and consistent output. Quality of a print is actually measured by its color gamut and every printers aim is to get the optimum print quality by controlling the process variables. The smoothness and roughness factor of printing paper has a significant role in producing maximum color gamut[2]. When ink is laid on the paper substrate, the ink will try to penetrate into the pores of the paper and the vehicle whether it is water or solvent tries to evaporate or get absorbed and pigment will settle on the surface. Surface roughness of the paper will affect the pigment deposition and this also contributes for the reduction in the color gamut [3].

When inkjet printers are used to produce the proofs for color matching or photograph printing, it is very difficult to get the color match in a regular printing or writing paper. For this reason papers are manufactured especially for inkjet printers.
These papers are coated with different surface sizing materials to improve their print quality. These coatings make the surface glossier, smoother and fill the pores of the paper to reproduce a higher color gamut [4]. Due to these coatings the spreading, absorption and light reflection of the ink layer will be improved and that is why a proofing paper will give higher color gamut than that can be produced in a writing and regular printing paper [5]. The surface coating is prepared with some optical brightening agents (OBA) that further improves the reflection, color gamut, print stability and light fastness on inkjet coated papers [6].

Most of the ink jet inks are standardized in terms of their optical and physical properties. So there will not be any such variations in the ink for a particular manufacturer. But another major parameter which is of serious concern is the printer condition and the settings. To bring the printer in a standard condition or to stabilize it a linearization process is carried out. With linearization a printer is said to be in a controlled position. A consistent and good quality print is possible only if the printer is linearized using some software for each and every combination of paper and image profile. [7].

Linearization and printing is accomplished using different raster imaging processing [RIP] tools. Every printer is supplied with its own RIP software and we can also use some other third party RIP software also. When different RIP 
software is used the color gamut may vary, especially in case of RGB platform as each RIP has its own color conversion algorithms which cannot be controlled by the user. But in CMYK platform it will not produce much more difference in color gamut [8].

Linearization is also carried out to understand the maximum and minimum print density of the printer. These values are denoted by $D_{\max }$ and $D_{\text {min }}$ which provides an idea about the maximum and minimum ink film thickness that can be deposited by this printer on a certain paper at particular printer settings. $\mathrm{D}_{\max }$ and $\mathrm{D}_{\min }$ of inkjet printer depends on the ink formulations, nozzle settings and the mechanism used for ink deposition and these values also contribute for increasing color gamut in the printer [9].

Along with linearization of the printer the next most important print attribute which will affect the quality of color is the image settings. The resolution, dot shape, screen angles and the dpi of the image are of most important to get a high quality image without affecting the clarity of the original image. As the printer resolution is increased it will produce an image which will be more like a continuous tone and beyond a certain limit there will not be any further increase in the color gamut. So a printer should know the optimum resolution for a particular dot shape, screen angle, paper, dpi and for the printer. It is also true that different dot shapes will result in different amount of dot gain which will be further supported by the resolution. Screen angle is one which is to be controlled to get a clear image without any moiré pattern [10].

\section{METHODOLOGY}

The project "Evaluation of quality of output in Epson inkjet Printer using Design of experiment method" is carried out using the following steps. Two types of paper substrates, Gloss (Epson Proofing commercial 187 GSM) and Matte (Epson Semi matte proofing paper $90 \mathrm{GSM}$ ) with different optical and physical properties were selected. Optical and physical properties of the paper substrate were measured using appropriate testing devices. Epson stylus Pro 7900, inkjet printer was selected and its initial settings and nozzle checking were carried out as per the manufacturer's instructions. post RIP software is installed in the system to produce the output through Epson Printer. Two types of dot shapes, round and elliptical were selected and these dot shapes were printed on the above said papers with two different resolutions $720 \times 720$ and 1440× 1440 maintaining screen angle for CYAN15, Magenta 75, Yellow 0 and Black 135 degrees. Linearization and calibration of the Epson ink jet printer is done using the RIP software for both types of paper at two different resolutions and dot shapes. Characterisation and standardisation of the Epson printer was done for two types of paper at two different resolutions and dot shapes. Test target IT8.7-3 CMYK(fig 1.) is generated using X-Rite Profile Maker 5.5 software to evaluate the print quality by measuring color gamut in the Epson printer. Test target was printed on two types of papers using post RIP software at two resolutions and at two types of dot shapes. The color values of printed test targets were measured using $\mathrm{iliO}$ spectrophotometer in conjunction with X Rite Profile Maker 5.5 measure tool software and profile for these measured data were generated using CHROMIX Color Think Pro software. Color gamut values[2] were tabulated into MiniTab software for analysing at three factors and two level experiments using Design of Experiment method. Subsequently the analysis was made. 


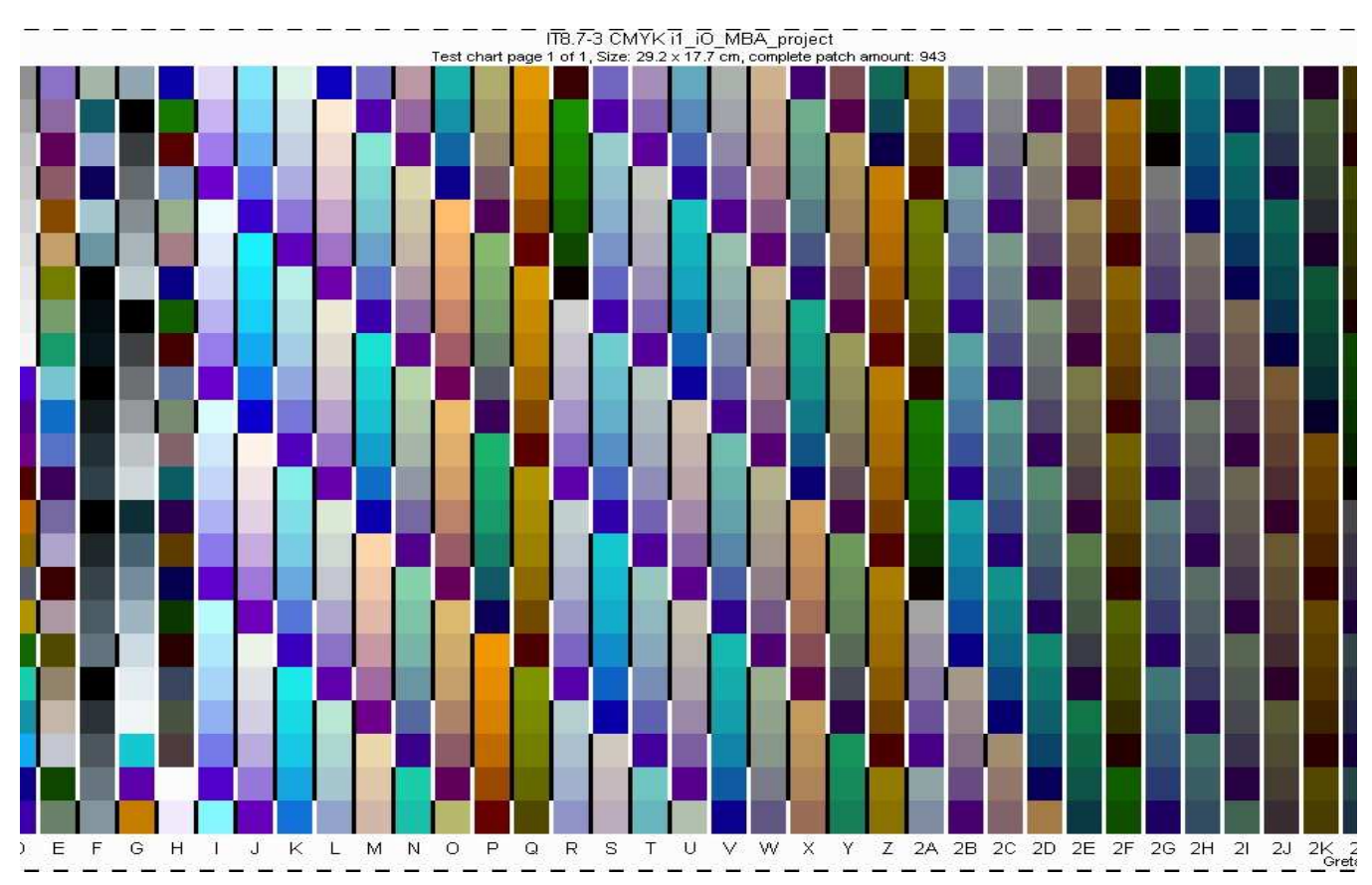

Fig 1 IT8.7-3 CMYK iliO Test target

\section{RESEARCH FINDINGS}

Table 1 Opacity values of two types of paper substrates

\begin{tabular}{|c|c|c|c|c|c|c|c|}
\hline Paper Name & $\begin{array}{l}\text { Reflectance } \\
\text { (black } \\
\text { backing) } \\
\text { \% Rb }\end{array}$ & $\begin{array}{l}\text { Reflectance } \\
\text { (White } \\
\text { backing) } \\
\text { \% Rw }\end{array}$ & $\begin{array}{l}\text { Reflectance } \\
\text { (Paper } \\
\text { backing) } \\
\text { \% Rp }\end{array}$ & $\begin{array}{l}\text { Print } \\
\text { Opacity } \\
\text { ( Rb/Rp) \% }\end{array}$ & $\begin{array}{l}\text { Opacity } \\
\text { Contrast } \\
\text { (Rb/Rw) } \\
\%\end{array}$ & $\begin{array}{l}\text { Averag } \\
\text { e Print } \\
\text { Opacity } \\
\%\end{array}$ & $\begin{array}{l}\text { Average } \\
\text { Opacity } \\
\text { Contrast } \\
\%\end{array}$ \\
\hline \multirow{3}{*}{$\begin{array}{lr}\text { Epson } & \text { Proofing } \\
\text { commercial } & \text { Paper } \\
187 \text { GSM } & \end{array}$} & 87.9 & 93.7 & 93 & 94.52 & 93.81 & \multirow{3}{*}{96.38} & \multirow{3}{*}{95.83} \\
\hline & 90.3 & 93.1 & 92.6 & 97.52 & 96.99 & & \\
\hline & 90.6 & 93.7 & 93.3 & 97.11 & 96.69 & & \\
\hline \multirow{3}{*}{$\begin{array}{l}\text { Epson Semi matte } \\
\text { Proofing paper } 90 \\
\text { GSM }\end{array}$} & 82.4 & 89.3 & 86.8 & 94.93 & 92.27 & \multirow{3}{*}{94.11} & \multirow{3}{*}{92.41} \\
\hline & 81.8 & 88.4 & 87 & 94.02 & 92.53 & & \\
\hline & 81.6 & 88.3 & 87.4 & 93.36 & 92.41 & & \\
\hline
\end{tabular}

Table 2 Brightness and $\mathrm{L}$ a b color values of two types of paper substrates

\begin{tabular}{|c|c|c|c|c|c|c|c|c|}
\hline \multirow{2}{*}{ Paper } & \multicolumn{2}{|c|}{ Brightness (\%) } & \multicolumn{2}{|l|}{$\mathbf{L}$} & \multicolumn{2}{|l|}{$\mathbf{a}$} & \multicolumn{2}{|l|}{ b } \\
\hline & Values & Average & $\mathbf{L}$ & Average & $\mathbf{a}$ & Average & B & Average \\
\hline \multirow{3}{*}{$\begin{array}{lr}\text { Epson } & \text { Semi } \\
\text { Matte } & \text { Proofing } \\
\text { paper } 90 & \text { GSM }\end{array}$} & 83.40 & \multirow{3}{*}{83.63} & 91.28 & \multirow{3}{*}{90.86} & 2.86 & \multirow{3}{*}{2.72} & $\begin{array}{l}-3.69 \\
\end{array}$ & \multirow{3}{*}{-3.95} \\
\hline & 83.40 & & 91.35 & & 2.89 & & -3.76 & \\
\hline & 84.10 & & 89.95 & & 2.42 & & $\begin{array}{l}-4.39 \\
\end{array}$ & \\
\hline \multirow{3}{*}{$\begin{array}{l}\text { Epson Proofing } \\
\text { commercial } \\
\text { Paper } 187 \text { GSM }\end{array}$} & 88.80 & \multirow{3}{*}{88.80} & 93.96 & \multirow{3}{*}{94.02} & 2.00 & \multirow{3}{*}{1.99} & -2.75 & \multirow{3}{*}{-2.73} \\
\hline & 88.90 & & 93.98 & & 2.02 & & -2.81 & \\
\hline & 88.70 & & 94.12 & & 1.96 & & -2.64 & \\
\hline
\end{tabular}


Table 3.Gloss values of two types of paper substrates

\begin{tabular}{|c|c|c|c|c|c|c|}
\hline \multirow{3}{*}{ Paper } & \multicolumn{6}{|c|}{ GLOSS Values( GU) } \\
\hline & \multicolumn{2}{|c|}{20 Degree } & \multicolumn{2}{|c|}{60 Degree } & \multicolumn{2}{|c|}{85 Degree } \\
\hline & Values & $\begin{array}{l}\text { Average } \\
\text { Gloss (20 } \\
\text { Degree) } \\
\end{array}$ & Values & $\begin{array}{l}\text { Average } \\
\text { Gloss ( } 60 \\
\text { Degree) }\end{array}$ & Values & $\begin{array}{l}\text { Average } \\
\text { Gloss (85 } \\
\text { Degree) } \\
\end{array}$ \\
\hline \multirow{3}{*}{$\begin{array}{l}\text { Epson Semimatte } \\
\text { Proofing paper } 90 \\
\text { GSM }\end{array}$} & 2 & \multirow{3}{*}{2} & 3.6 & \multirow{3}{*}{3.60} & 9.40 & \multirow{3}{*}{9.50} \\
\hline & 2 & & 3.6 & & 9.30 & \\
\hline & 2 & & 3.6 & & 9.80 & \\
\hline \multirow{3}{*}{$\begin{array}{l}\text { Epson Proofing } \\
\text { commercial Paper } \\
187 \text { GSM }\end{array}$} & 15.6 & \multirow{3}{*}{17.8} & 55.1 & \multirow{3}{*}{55.63} & 93.80 & \multirow{3}{*}{92.83} \\
\hline & 18.9 & & 55.7 & & 90.60 & \\
\hline & 18.9 & & 56.1 & & 94.10 & \\
\hline
\end{tabular}

Table 4 Comparison of color gamut in various combinations of print parameters

\begin{tabular}{|l|l|l|l|}
\hline Name of the paper & Dot Shape & Resolution & $\begin{array}{l}\text { Color Gamut } \\
\text { (Number of colors) }\end{array}$ \\
\hline Epson Proofing Commercial(187 GSM) & Round & $720 \times 720$ & 437289 \\
\hline Epson Proofing Commercial(187 GSM) & Round & $1440 \times 1440$ & 460105 \\
\hline Epson Proofing Commercial(187 GSM) & Elliptical & $720 \times 720$ & 440085 \\
\hline Epson Proofing Commercial(187 GSM) & Elliptical & $1440 \times 1440$ & 474562 \\
\hline Epson Semi Matte Proofing (90 GSM) & Round & $720 \times 720$ & 265433 \\
\hline Epson Semi Matte Proofing (90 GSM) & Round & $1440 \times 1440$ & 282805 \\
\hline Epson Semi Matte Proofing (90 GSM) & Elliptical & $720 \times 720$ & 270908 \\
\hline Epson Semi Matte Proofing (90 GSM) & Elliptical & $1440 \times 1440$ & 285338 \\
\hline
\end{tabular}

Table 5 Factors and levels for Design of experiment

\begin{tabular}{|l|l|l|l|}
\hline Factors & Paper type & Dot shape & Resolution(DPI) \\
\hline Level 1 & Epson Semi matte proofing paper (90 GSM) & Round & $720 \times 720$ \\
\hline Level 2 & Epson Proofing commercial paper (187 GSM) & Elliptical & $1440 \times 1440$ \\
\hline
\end{tabular}

Table 6 Combination of factors and levels in MiniTab software full factorial design

\begin{tabular}{|l|l|l|l|l|l|l|}
\hline $\begin{array}{l}\text { Std } \\
\text { order }\end{array}$ & $\begin{array}{l}\text { Run } \\
\text { Order }\end{array}$ & Center Pt & Blocks & Paper Type & Dot shape & Resolution \\
\hline 2 & 1 & 1 & 1 & Epson Comm & Round & 720 \\
\hline 7 & 2 & 1 & 1 & Semi Matte & Elliptical & 1440 \\
\hline 1 & 3 & 1 & 1 & Semi Matte & Round & 720 \\
\hline 3 & 4 & 1 & 1 & Semi Matte & Elliptical & 720 \\
\hline 8 & 5 & 1 & 1 & Epson Comm & Elliptical & 1440 \\
\hline 5 & 6 & 1 & 1 & Semi Matte & Round & 1440 \\
\hline 6 & 7 & 1 & 1 & Epson Comm & Round & 1440 \\
\hline 4 & 8 & 1 & 1 & Epson Comm & Elliptical & 720 \\
\hline
\end{tabular}




\section{ANALYSIS}

\subsection{Full Factorial Design}

$\begin{array}{lll}\text { Factors: } 3 & \text { Base Designs: } & 3,8 \\ \text { Runs: } & 8 & \text { Replicates: }\end{array}$

Blocks: $1 \quad$ Center pts (total): 0

All terms are free from aliasing.

\subsection{Design Table (randomized)}

\begin{tabular}{|cccc|}
\hline Run A B C \\
\hline 1 & + & - & - \\
\hline 2 & - & + & + \\
\hline 3 & - & - & - \\
\hline 4 & - & + & - \\
\hline 5 & + & + & + \\
\hline 6 & - & - & + \\
\hline 7 & + & - & + \\
\hline 8 & + & + & - \\
\hline
\end{tabular}

Factorial Fit: Color Gamut versus Paper Type, Dot shape, Resolution

\subsection{Estimated Effects and Coefficients for Color}

Gamut (coded units)

\begin{tabular}{|lccccc|}
\hline Term & Effect & Coef & SE Coef & T & P \\
\hline Constant & 364566 & 1825 & 199.72 & 0.003 & \\
\hline Paper Type & 176889 & 88445 & 1825 & 48.45 & 0.013 \\
\hline Dot shape & 6315 & 3158 & 1825 & 1.73 & 0.334 \\
\hline Resolution & 22274 & 11137 & 1825 & 6.10 & 0.103 \\
\hline Paper Type*Dot shape & 2311 & 1156 & 1825 & 0.63 & 0.641 \\
\hline Paper Type*Resolution & 6373 & 3186 & 1825 & 1.75 & 0.331 \\
\hline Dot shape*Resolution & 2180 & 1090 & 1825 & 0.60 & 0.657 \\
\hline
\end{tabular}

$\mathrm{S}=5162.94 \quad$ PRESS $=1705980872$

$\mathrm{R}-\mathrm{Sq}=99.96 \% \quad \mathrm{R}-\mathrm{Sq}($ pred $)=97.33 \% \quad \mathrm{R}-\mathrm{Sq}(\operatorname{adj})=99.71 \%$

\subsection{Analysis of Variance for Color Gamut (coded} units)

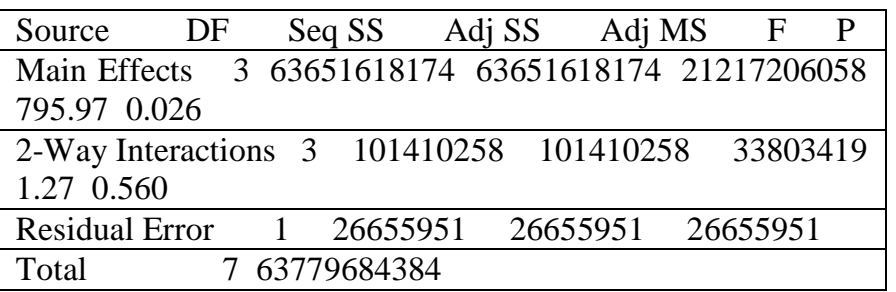

\subsection{Estimated Coefficients for Color Gamut using} data in un coded units

\begin{tabular}{|ll|}
\hline Term & Coef \\
\hline Constant & 331155 \\
\hline Paper Type & 78885.5 \\
\hline Dot shape & -112.00 \\
\hline Resolution & 30.9358 \\
\hline Paper Type*Dot shape 1155.63 \\
\hline Paper Type*Resolution 8.85104 \\
\hline Dot shape*Resolution 3.02743 \\
\hline
\end{tabular}

\subsection{Least Squares Means for Color Gamut}

\subsection{Paper Type}

$$
\text { Mean SE Mean }
$$

\begin{tabular}{|lll|}
\hline Semi Matte & 276121 & 2581 \\
\hline Epson Comm & 453010 & 2581 \\
\hline
\end{tabular}

\subsection{Dot shape}

\begin{tabular}{|lcc|}
\hline Round & 361408 & 2581 \\
\hline Elliptical & 367723 & 2581 \\
\hline
\end{tabular}

\subsection{Resolution}

\begin{tabular}{|lcc|}
\hline 720 & 353429 & 2581 \\
\hline 1440 & 375703 & 2581 \\
\hline
\end{tabular}

\subsection{Paper Type*Dot shape}

\begin{tabular}{|lcc|}
\hline Semi Matte Round & 274119 & 3651 \\
\hline Epson Comm Round & 448697 & 3651 \\
\hline Semi Matte Elliptical & 278123 & 3651 \\
\hline Epson Comm Elliptical & 457324 & 3651 \\
\hline
\end{tabular}

$$
\text { Mean SE Mean }
$$

\subsection{Paper Type*Resolution}

\begin{tabular}{|lcc|}
\hline Semi Matte 720 & 268171 & 3651 \\
\hline Epson Comm 720 & 438687 & 3651 \\
\hline Semi Matte 1440 & 284072 & 3651 \\
\hline Epson Comm 1440 & 467334 & 3651 \\
\hline
\end{tabular}

\subsection{Dot shape*Resolution}

\begin{tabular}{|lcc|}
\hline Round 720 & 351361 & 3651 \\
\hline Elliptical 720 & 355497 & 3651 \\
\hline Round 1440 & 371455 & 3651 \\
\hline Elliptical 1440 & 379950 & 3651 \\
\hline
\end{tabular}




\subsection{Effects Plot for Color Gamut and Pareto for Color Gamut}

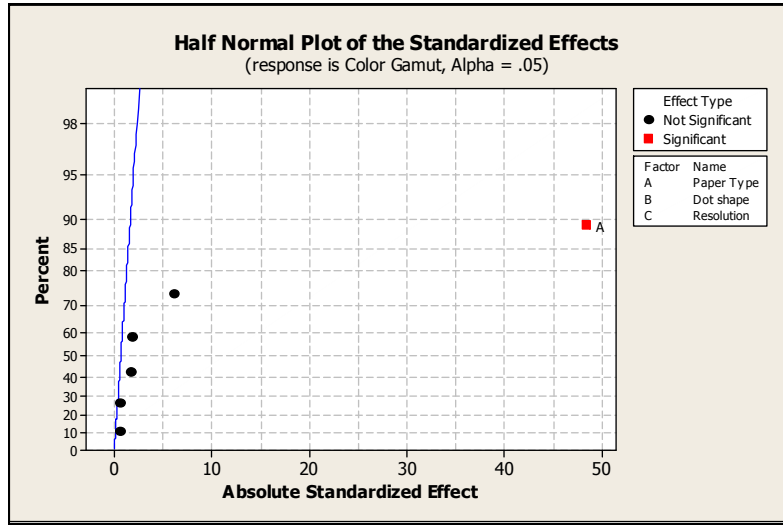

(a)

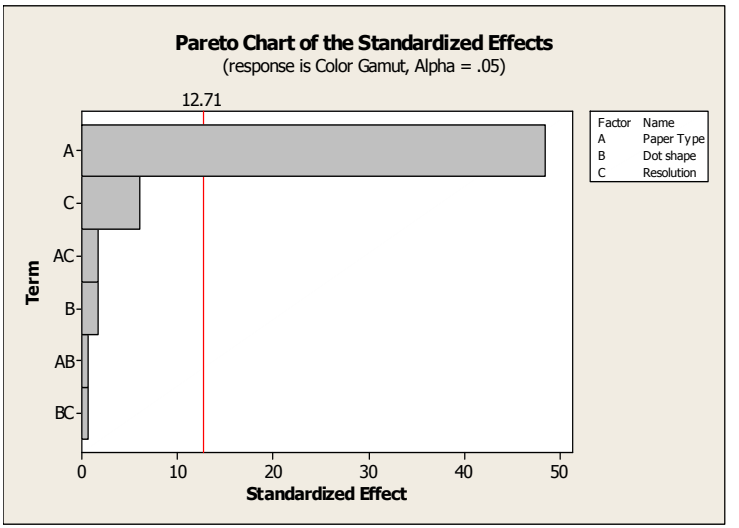

(b)

Fig. 2 (a) Half Normal plot and (b) Pareto Chart of the Standardized effects

\subsection{Half Normal Effects Plot and Residual Plots for Color Gamut}

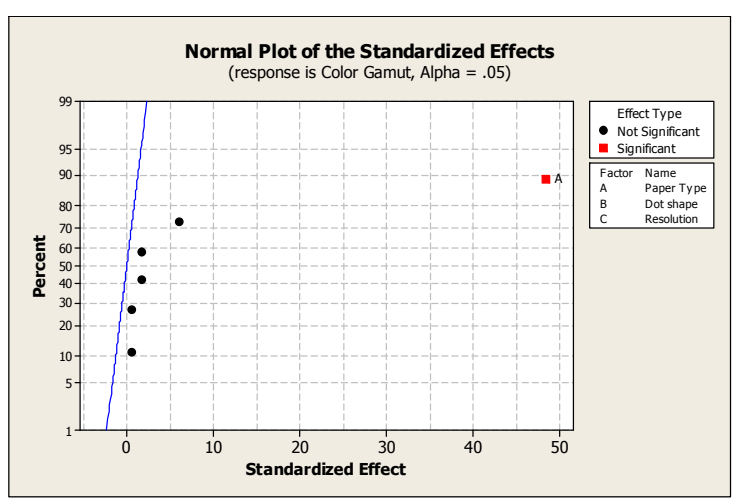

(c)

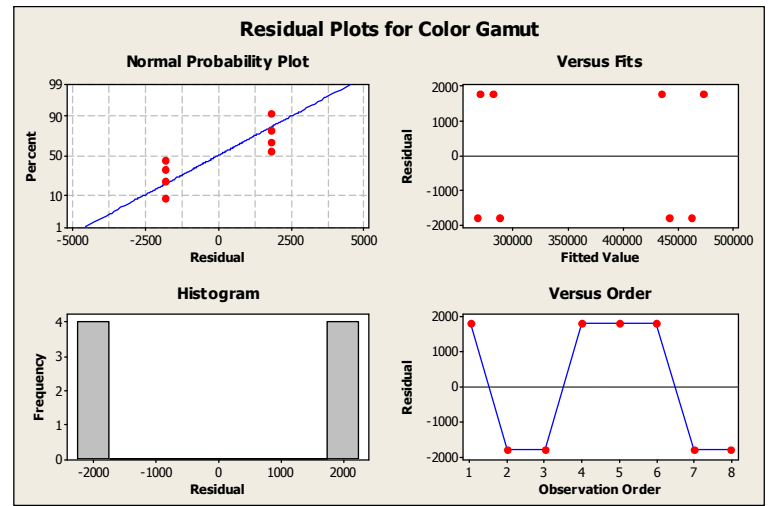

(d)

Fig. 3 Normal Plot of the standardised effects and Residual plots for color gamut

\section{CONCLUSION FROM THE DESIGN OF EXPERIMENT OUTPUT:}

The analysis of variance table gives a summary of the main effects and interactions. This shows that Main effects are significant than two way interactions.
Effect P-Value
Main Effects 0.026

$$
\begin{gathered}
\text { Significant* } \\
\text { yes }
\end{gathered}
$$

Two-way interactions 0.560 no $*$ significant at alpha $=0.05$ After identifying the significant effects (main effect) in the analysis of variance table, the estimated effects and coefficients table shows the p-values associated with each individual model term. The $\mathrm{p}$ values indicate that just one main effects paper $(\mathrm{p}=0.013)$ is significant. Paper type has a maximum effect of 176889 on the color gamut and it is significant as $\mathrm{p}$ value is below 0.05 . Next term that is having highest effect is resolution but it is not significant as its $p$ value is greater than 0.05 .

In the normal probability plot of the effects, points that do not fall near the line usually signal important effects. Important effects are larger and further from the fitted line than unimportant effects. Unimportant effects tend to be smaller and centered around zero. The normal probability plot uses $\alpha$ 
$=0.05$, by default. The plot in this experiment shows that term paper is only significant and dot shape and resolution change are insignificant.

The Pareto chart displays the absolute value of the effects and draws a reference line on the chart. Any effect that extends past this reference line is potentially important. The reference line corresponds to alpha $=0.05$, by default. From the Pareto graph generated in this experiment shows the paper only as the significant term.

The DOE analysis says that the change in dot shape from round to elliptical and resolution from $720 \times 720$ to $1440 \mathrm{x}$ 1440 dpi has not shown any significant changes in comparison with the change of paper substrate. This is quite obvious due to the small change in the dot shape from round to elliptical and due to the higher end resolution that was selected for the printing. If the dot shapes selected were round and square or square and elliptical there would have some significant results on color gamut. Similarly the printer shows similar color gamut when it is printed using $720 \times 720$ or $1440 \times 1440 \mathrm{dpi}$ resolutions this is due to the fact that both resolutions are of high end and printing with $720 \times 720 \mathrm{dpi}$ is optimum for paper substrates. In addition to this when an optimum resolution is achieved i.e. $720 \times 720 \mathrm{dpi}$ as here further increase in the ink deposition will not contribute for enhancing color but instead it will increase the amount of ink deposition and its consumption which is not economical. The result would have some significant effect if it printed with $720 \times 720$ dpi and $360 \times 360$ dpi or other dpi of lower range.

The DOE analysis strongly says here that change from Epson semi matte proofing paper (90GSM) to Epson proofing commercial (187 GSM) has a significant change in the color gamut. When we compare the optical properties of these paper grades, we can see that opacity, brightness and $\mathrm{L}$ a $\mathrm{b}$ values of these papers are somewhat similar with smallest variation. But when we compare the gloss there is a huge change in their property. To get the gloss normally paper substrates are coated and calendared with special treatment during manufacturing. The glossy surface makes the light to reflect in specular way and since these surfaces are coated they will not allow ink to get absorbed into the pores of the fibers and due to these properties of the coating the pigments of the ink will stay on paper surface and reflect all the colors resulting in maximum color gamut.

The residual plot versus Fits and fitted value is expected to have values uniformly spread above, below and throughout the length of the zero line then the model is correct on average for all fitted values. In our experiment due to lack of data we could see only eight values but they are equally distributed from zero level so the model is quite fine and it is random in nature. The Normal Probability plot also expected to have the residual plots values uniformly aligned with the reference line to conclude the errors are distributed normally and the normality of errors assumption is valid. But in our experiment they are not so aligned and more data might be required to get clearer picture.

\section{SCOPE FOR FURTHER WORK}

In this experiment the two types of dot shapes taken were having similar curvature and that could be the one reason for having no significance of the dot shape on the color gamut. There are so many other dot shapes available in the RIP software, which have square, line and other shapes and using such dot shapes similar experiment can be performed to see whether the dot shape is significant or not. The two resolutions taken for this experiment are of high end and found no significant effect on the color gamut. The resolution options available are vary from printer to printer and similar study can be conducted to see their significance level.

The entire project is carried at a constant screen angle which is one of the standards screen angle followed by the printing industry. Some the printers based on the type of image whether it is high key or low key pictures screen angle is changed for individual colors. Further study can be planned for other industry standard screen angles.

The significant factor that was found in this experiment was the paper type. The glossy surface of the paper had significant effect and the color gamut was nearly double when paper is changed from semi matte surface to glossy surface. This experiment can also be used by the paper manufacturer to evaluate the improvements that happens due to the surface modification of the paper on the color output.

\section{REFERENCES}

[1] Bandyopadhyay.S., Jadhavpur University (India), "Effect of paper properties on print quality of inkjet printer, proceedings of IS \& T s, NIP17, International Conference on Digital Printing Technology, p 141-144 ,(2001)

[2] Chovancova Lovell, V.L, Fleming P.D, "Effect of optical brightening agents \& UV protective coatings on print stability of the fine art substrates for inkjet", Proceedings of the IS \& T NIP 22, international conference on digital printing technologies, Denver, September 17-22, p 227-230, (2006)

[3] E.Hrehorova, A.Sharma, P.D.Fleming, "Colour reproduction studies in RGB \& CMYK workflows using inkjet printer drivers \& RIP's", Proceedings of the $58^{\text {th }}$ TAGA annual technical conference (2006)

[4] Isabel M. T. Moutinho,a,* Paulo J. T. Ferreira,b and Margarida L. Figueiredo F.b (2011) "Paper surface for inkjet," BioResources 6(4), 4259-4270.

[5] Livens \& Mahy 2002, "Quality managed proofing- the road to visual consistency", presented at the $29^{\text {th }}$ 
International IARIGAI Research conference September 8-11, 2002, Switzerland.

[6] Marguerite Doyle, "Measuring the imperfect dot", IS\&T's NIP 16, International Conference on Digital Printing Technologies ,(2000).

[7] Renmei Xu, Paul D Fleming \& Alexandra P, "The effect of inkjet paper roughness on print gloss" ,Journal of Imaging Science and Technology, vol 49,Issue No 6, November / December 2005, p 660-665

[8] Trish Wales, "Paper; the fifth color", IPA bulletin, May /June ,2008

[9] Torry Pines research, Carlsbad, CA 92009, "Inkjet Print Image quality considerations", March 2003, www.tpr.com

[10] Yu Ju Wu, Pekarovicova, A. and Fleming P. D., "How Paper Properties Influence color reproduction of digital proofs for publication gravure", TAGA, 527- 544 (2007). 